\title{
THE PHOTOSYNTHETIC PHYSIOLOGY AND GROWTH RESPONSE OF TWO ALGAE SPECIES, MICROCYSTIS AERUGINOSA AND SCENEDESMUS QUADRICAUDA, TO DIFFERENT NITROGEN FORMS AND CONCENTRATIONS
}

\author{
HE, Y. J. ${ }^{1}-$ WANG, R. ${ }^{1}-$ MA, D. L. ${ }^{1}-$ YIN, X. T. ${ }^{1}-$ YANG, K. F. ${ }^{1}$ TIAN, Y. N. ${ }^{1}-$ LIU, S. M. ${ }^{1}$ \\ ZHOU, C. X. ${ }^{2}-\mathrm{HOU}, \mathrm{X}$. L. $^{1 *}$ \\ ${ }^{1}$ College of Agronomy and Life Sciences, Kunming University, Kunming 650214, China \\ ${ }^{2}$ Yunnan Huanlv Environmental testing technology company, Kunming 650214, China \\ *Corresponding author \\ e-mail: hxlyn@aliyun.com \\ (Received $2^{\text {nd }}$ Sep 2020; accepted $19^{\text {th }}$ Jan 2021)
}

\begin{abstract}
Organic nitrogen and inorganic nitrogen were the main nitrogen sources in the north and south of Dianchi Lake, respectively. Thus, the effect of the different concentration $(0.5,1.0,2.0,5.0,10,20$, $50 \mathrm{mg} / \mathrm{L})$ of ammonium nitrogen $\left(\mathrm{NH}_{4}{ }^{+}-\mathrm{N}\right)$ and alanine on growth of Microcystis aeruginosa and

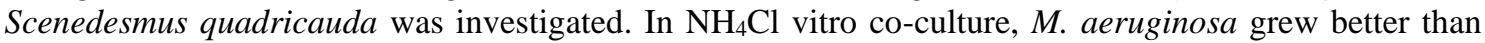
S. quadricauda, and its chlorophyll $a$ increased to $2893.94 \mathrm{ug} / \mathrm{L}$ in $2 \mathrm{mg} / \mathrm{L} \mathrm{NH} \mathrm{Cl}_{4}$ group. In vitro alanine treatments, S. quadricauda's chlorophyll $a$ was measured at $5034.34 \mathrm{ug} / \mathrm{L}$ in $50 \mathrm{mg} / \mathrm{L}$ alanine, which was higher than M. aeruginosa. M. aeruginosa in $\mathrm{NH}_{4} \mathrm{Cl}$ vitro monocultures showed better cell structure in $20 \mathrm{mg} / \mathrm{L} \mathrm{NH} \mathrm{NCl}_{4}$, and its chlorophyll $a$ was higher than that of the corresponding concentration of alanine. The photosynthetic activity $\left(\mathrm{F}_{\mathrm{v}} / \mathrm{F}_{\mathrm{m}}\right)$, the maximum electron transfers rate (ETRmax), and the saturated light intensity point $\left(\mathrm{I}_{\mathrm{k}}\right)$ of $M$. aeruginosa increased with the ammonium concentration, and decrease with the alanine concentration, indicating that $M$. aeruginosa can tolerate higher concentrations of ammonium chloride. In high concentrations of $\mathrm{NH}_{4} \mathrm{Cl}, \mathrm{S}$. quadricauda's cell was seriously damaged, but of alanine alone, it was intact. $\mathrm{F}_{\mathrm{v}} / \mathrm{F}_{\mathrm{m}}$, ETRmax, and $\mathrm{I}_{\mathrm{k}}$ of $S$. quadricauda increased with the alanine concentrations, showing that $S$. quadricauda makes better use of organic nitrogen.
\end{abstract}

Keywords: ammonium, alanine, chlorophyll a, fluorescence characteristic, photosynthesis, cyanobacterial blooms

\section{Introduction}

Nitrogen and phosphorus are key factors of eutrophic freshwater bodies, and the increase in concentrations is generally considered to be the radical cause of cyanobacteria blooms (Conley et al., 2009; Neil et al., 2013; Li et al., 2014; Wang et al., 2015). Outbreaks of cyanobacteria bloom have not been sufficiently prevented, and controlling the total concentration of nutrients is not effective in alleviating the bloom of cyanobacteria. In addition, nutrient morphology also has a corresponding impact on the growth, distribution and community structure of algae (Xu et al., 2019). Nitrogen in natural freshwater body can exist in many forms, for example, dissolved nitrogen not only exists in the form of soluble inorganic nitrogen such as nitrate nitrogen $\left(\mathrm{NO}_{3}{ }^{-}-\mathrm{N}\right)$, nitrite nitrogen $\left(\mathrm{NO}_{2}^{-}-\mathrm{N}\right)$, ammonium nitrogen $\left(\mathrm{NH}^{+}{ }_{4}-\mathrm{N}\right)$ but also in the form of soluble organic nitrogen such as amino acid, urea, amide, hypoxanthine, and guanine. The bioavailability of the nitrogen affects the absorption rate and utilization efficiency of algae. The utilization characteristics of different forms of nitrogen are closely related to the species of algae. It is generally believed that $\mathrm{NH}_{4}{ }^{+}-\mathrm{N}$ and $\mathrm{NO}_{3}{ }^{-}-\mathrm{N}$ are the main forms of nitrogen utilized by phytoplankton (Zhang et al., 2011). However, the presence of $\mathrm{NH}_{4}{ }^{+}-\mathrm{N}$ in water 
may inhibit the uptake of $\mathrm{NO}_{3}^{-}-\mathrm{N}$ by cyanobacteria (Zhu, 2007). The high concentration of $\mathrm{NH}_{4}{ }^{+}-\mathrm{N}$ has a certain toxic effect on algae (Tang et al., 2008; Zhang et al., 2011). The main form of organic nitrogen is an amino acid, which comes from phytoplankton. Algae regeneration and death degradation are intertwined, increasing of biomass and organic matter content in the water. In the process of algal bloom, some algal death degradation occurs, which lead to an increase of dissolved organic nitrogen in freshwater ( $\mathrm{Yu}$ et al., 2016). Therefore, understanding the relationship between amino acids and algal growth is necessary to further understand the ecological relationship between the change of organic matter concentration and algal population. However, some studies focused on the influence of inorganic nitrogen, mainly nitrate and orthophosphate, on algae and algal community structure, and extrapolated the relationship between the change in total concentration and algae growth proposing that the occurrence of cyanobacteria bloom can be controlled by limiting the content of total nitrogen and phosphorus (Wu et al., 2009; Zhu et al., 2018; Peng et al., 2018). However, through investigation of the succession of phytoplankton community in Dianchi Lake, Microcystis of cyanophyta and Scenedesmus of chlorophyta alternated with seasons. Dianchi lake was divided in 1996 by Haigeng dam into two parts, Caohai Bay in the north and Waihai lake in the south, respectively. The concentration of total nitrogen and total phosphorus in Caohai Bay is higher than that in Waihai lake. Scenedesmus qusdricauda becomes the dominant species in Caohai Bay in most months of the year, and their biomass is higher than that of cyanophyta, while the dominant species is cyanobacteria in Waihai lake (Shi et al., 2014; Hou et al., 2018). That is to say, freshwater bodies with high nitrogen and phosphorus concentrations are not the only factor for cyanobacteria bloom. The influence of nutrient concentration and form interaction on the growth of Microcystis aeruginosa and Scenedesmus qusdricauda in the freshwater body of Dianchi Lake needs further study.

$M$. aeruginosa and $S$. quadricauda which belongs to cyanobacteria and Chlorophyta respectively, are widely distributed in Dianchi Lake. Both of them belong to non-nitrogen fixing algae, so nutrients are one of the limiting factors for their growth. As an autotroph, the photosynthesis of the two species is closely related to the growth of algae and affects the physiological process (Jia et al., 2011). When the growth of algae is limited by available nitrogen, photosynthesis ability to catch light and energy transfer, and carbon fixation are damaged (Geider et al., 1993). Guo (2015) found that the effect of phosphorus concentration on photochemical efficiency of photosystem II (Fv/Fm) was not significant by analysis of the relation between phosphorus concentration and Fv/Fm of Cladophora oligoclora Kütz. The absorption and assimilation of inorganic nitrogen by photosynthetic organisms depends on the energy and carbon skeleton produced by photosynthesis and the metabolic process of nitrogen absorption in chloroplasts and mitochondria of algae, so nitrogen is a necessary ecological factor for energy transfer in photosynthesis (Young and Beardall, 2003). There is a certain relationship between the occurrence of nitrogen sources of different forms and concentrations with photosynthetic activity, photosynthetic efficiency and other parameters (Liu et al., 2019). Therefore, whether the form of the nitrogen source produces stress on algae or whether the ability of algae to resist adversity can be measured by using chlorophyll fluorescence parameters needs further study. Based on these discussions, this study takes $M$. aeruginosa and $S$. quadricauda, which are the dominant species of cyanobacteria and green algae in Dianchi Lake, as representative algal species. Alanine is a common amino acid in natural water, which makes up protein, while the ammonium nitrogen is an inorganic nitrogen widely existing in lake. So this study uses alanine and ammonium chloride as nitrogen sources, to explore the effects of 
different formations and concentrations of nitrogen on the growth of algae, and to study the relationship between the fluorescence parameters of algae from different nitrogen sources, and to explore the physiological response of M. aeruginosa and $S$. quadricauda to different nitrogen sources.

\section{Methods}

\section{Experimental design}

We chose Microcystis aeruginosa and Scenedesmus quadricauda from the Freshwater Algae Culture Collection of the Institute of Hydrobiology (FACHB-collection, Wuhan, China). These algae were cultured in medium in a light incubator under the condition of $25^{\circ} \mathrm{C}$, a dark/light period of $12 \mathrm{~h}: 12 \mathrm{~h}$, the light intensity of 3000-4000 lx, and shaken twice a day. The medium is BG11 which is composed of $\mathrm{NaNO}_{3}, \mathrm{~K}_{2} \mathrm{HPO}_{4}, \mathrm{MgSO}_{4} \bullet 7 \mathrm{H}_{2} \mathrm{O}$, $\mathrm{CaCl}_{2} \bullet 2 \mathrm{H}_{2} \mathrm{O}$, Citric acid, EDTANa $, \mathrm{CaCO}_{3}, \mathrm{H}_{3} \mathrm{BO}_{3}, \mathrm{MnCl}_{2} \bullet 4 \mathrm{H}_{2} \mathrm{O}, \mathrm{ZnSO}_{4} \bullet 7 \mathrm{H}_{2} \mathrm{O}$, $\mathrm{Na}_{2} \mathrm{MoO}_{4} \cdot 2 \mathrm{H}_{2} \mathrm{O}, \mathrm{CuSO}_{4} \cdot 5 \mathrm{H}_{2} \mathrm{O}, \mathrm{Co}\left(\mathrm{NO}_{3}\right) \cdot 6 \mathrm{H}_{2} \mathrm{O}$. M. aeruginosa and $S$. quadricauda cells were collected in the logarithmic growth period by centrifugation (4000 rpm, $8 \mathrm{~min}$ ). We rinsed two algae 3 times by $\mathrm{N}$-free medium and then inoculated in a medium for $48 \mathrm{~h}$ to exhaust nutrients stored in cells. Then, alanine and ammonium nitrogen were used as nitrogen sources with a $5 \mathrm{~g} / \mathrm{L}$ concentration of nitrogen and was filtered using a $0.22 \mu \mathrm{m}$ microporous membrane. The concentration gradient of ammonium nitrogen and alanine in each treatment group was $0.5,1.0,2.0,5.0,10,20,50 \mathrm{mg} / \mathrm{L}$. The experiment was divided into three groups. In the first group, $M$. aeruginosa were separately cultured in alanine and ammonium nitrogen at the above $\mathrm{N}$ concentration gradient. In the second group, monocultures of $S$. quadricauda were separately exposed to two nitrogen sources, alanine and ammonium, under the same $\mathrm{N}$ concentration gradient. In the third group, $M$. aeruginosa and $S$. quadricauda were cultured together at the above N concentration gradient with respectively ammonium nitrogen and alanine. Before combining $M$. aeruginosa and $S$. quadricauda into a co-culture, we counted the algae cells under the microscope to ensure that the number of algae cells is approximately the same value with $1.7 \times 10^{6}$ cells $/ \mathrm{ml}$. In all, each treatment group of the experiment was performed in triplicate. Each treatment group was cultured for 18 days, and $3 \mathrm{ml}$ of algal solution in each treatment group was taken every 2 days for determination of physiological characteristics and chlorophyll $a$. At the end of culture period, the cell morphology of two algal was monitored under a microscope and the morphological pictures were obtained by scope photo 3.0 .

\section{Analytical methods}

The chlorophyll fluorescence characteristic of algae was determined by phyto PAM (Walz, Germany). Samples need to be dark-adapted for 20 minutes. Then, chlorophyll fluorescence technology is a vivo measurement technology to detect the photosynthetic physiological status and the subtle influence of the external environment on algae which is based on using chlorophyll as an indicator of fitness. The Hansatech Flurescence Monitoring System PAM (Phyto-PAM, WALZ, Germany) was used to measure the chlorophyll $a$, chlorophyll fluorescence parameter of $M$. aeruginosa and $S$. quadricauda every two days in cultural period. The maximum photochemical efficiency (Fv/Fm) of photosystem II (PSII) is to measure the maximum chlorophyll fluorescence (Fm) of algal cells under dark adaptation. The formula described by Genty et al. (1989) is as follows: 
$\mathrm{Fv} / \mathrm{Fm}=(\mathrm{Fm}-\mathrm{Fo}) / \mathrm{Fm}$, where $\mathrm{Fm}$ is the maximum fluorescence, which is measured when all reaction centers of PSII are completely closed and all non-photochemical processes are in the minimum under dark adaptation state. Fo is the initial fluorescence, which is the fluorescence value when all reaction centers of PSII are completely open and all nonphotochemical processes are in the minimum under dark adaptation state. Fv is the maximum variable fluorescence when all non-photochemical processes are in the minimum under dark adaptation state, $\mathrm{Fv}=\mathrm{Fm}$ - Fo. According to Ting and Owens (1992), the rapid light curve was measured under nine light intensity gradients $(90,162,226,334$, $486,707,1075,1586,2343 \mu \mathrm{mol} \cdot \mathrm{m}^{-2} \mathrm{~s}^{-1}$ ). The relative electron transfer rate of PSII (ETR) is calculated by the formula as follows: $\mathrm{rETR}=$ Yield $\times 0.5 \times \mathrm{PFD}$, where Yield is the effective photochemical efficiency of PSII, the coefficient of 0.5 represents that $50 \%$ of all absorbed photons are allocated to PSII, PFD is the intensity of photochemical light. The maximum relative electron transfer rate (ETRmax) and photosynthetic efficiency (a) were obtained by fitting the rapid light response curve with original software (8.0) according to the exponential formula ETR $=$ ETRmax $\times[1-\exp (-\mathrm{a} \times \mathrm{PFD} / \mathrm{ETRmax})]$. The semi-saturated light intensity $\left(\mathrm{I}_{\mathrm{k}}\right)$ reflects the tolerance of the sample to strong light, and the calculation formula is as follows: $\mathrm{I}_{\mathrm{k}}=\mathrm{ETRmax} / \mathrm{a}$. The average chlorophyll $a$ and chlorophyll fluorescence parameter of $M$. aeruginosa and $S$. quadricauda were caculated by Microsoft Excel (2010) and Origin 8.0 software.

\section{Result}

\section{Comparison of chlorophyll a content of M. aeruginosa and S. quadricauda in co- culture experiment with separately two nitrogen sources}

The content of chlorophyll $a$ of $M$. aeruginosa and $S$. quadricauda in a co-cultured experiment with different concentrations of alanine as nitrogen source is shown in Figure 1. The utilization advantage of alanine by $S$. quadricauda is higher than that of $M$. aeruginosa. The content of chlorophyll $a$ of $S$. quadricauda was higher than that of $M$. aeruginosa, and increased with alanine concentration during the co-culture period. However, the chlorophyll $a$ content of $M$. aeruginosa decreased with time in co-culture experiment. After co-culture in 12 days, the content of chlorophyll $a$ of $S$. quadricauda in the group of $50 \mathrm{mg} / \mathrm{L}$ alanine was as high as $5034.34 \mathrm{ug} / \mathrm{L}$, followed by that in the treatment group of $20 \mathrm{mg} / \mathrm{L}$ alanine, which was $4076.58 \mathrm{ug} / \mathrm{L}$. At the end of co-culture period, the content of chlorophyll $a$ in $M$. aeruginosa was $0 \mathrm{mg} / \mathrm{L}$. In the range of $0.5-5$ $\mathrm{mg} / \mathrm{L}$ alanine concentration, the content of chlorophyll $a$ of $S$. quadricauda was between 2603.93-2706.78 ug/L. The highest chlorophyll $a$ of $M$. aeruginosa was $339.38 \mathrm{ug} / \mathrm{L}$, which was far lower than that of $S$. quadricauda.

The content of chlorophyll $a$ of two algae species in the co-cultured experiment with different concentrations of ammonium is shown in Figure 2. In different concentrations of ammonium treatment group, the chlorophyll $a$ in $M$. aeruginosa was higher than that of $S$. quadricauda, which indicated that the utilization advantage of $M$. aeruginosa to ammonium chloride was higher than that of $S$. quadricauda. The M. aeruginosa's chlorophyll $a$ rose with the culture time, while the chlorophyll $a$ of $S$. quadricauda showed the opposite trend. After 16 days of co-culture, the chlorophyll $a$ content of $M$. aeruginosa in each ammonium treatment group was twice the initial content, and the highest content of chlorophyll $a$ of it was $2893.94 \mathrm{ug} / \mathrm{L}$ in the $2 \mathrm{mg} / \mathrm{L} \mathrm{NH}_{4} \mathrm{Cl}$ group. In the entire culture cycle, the highest chlorophyll $a$ of $S$. quadricauda was $891.14 \mathrm{ug} / \mathrm{L}$, which was far lower than that of $M$. aeruginosa. 


$$
\text { - } 1611 \text { - }
$$
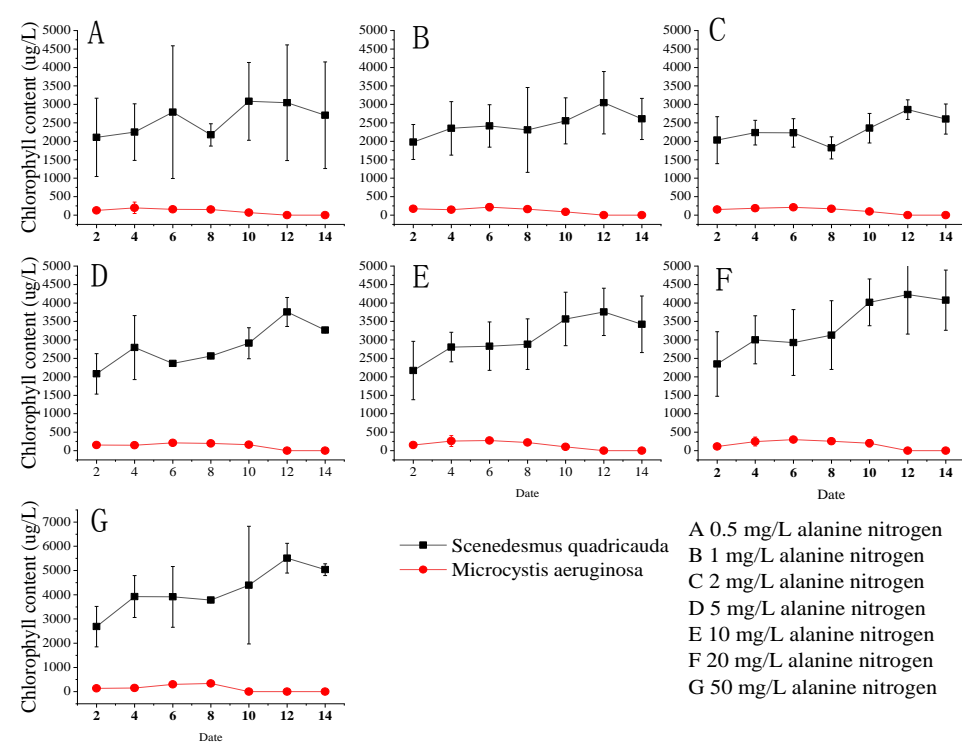

A $0.5 \mathrm{mg} / \mathrm{L}$ alanine nitrogen B $1 \mathrm{mg} / \mathrm{L}$ alanine nitrogen C $2 \mathrm{mg} / \mathrm{L}$ alanine nitrogen D $5 \mathrm{mg} / \mathrm{L}$ alanine nitrogen E $10 \mathrm{mg} / \mathrm{L}$ alanine nitrogen F $50 \mathrm{mg} / \mathrm{L}$ alanine nitrogen

Figure 1. Chlorophyll a of M. aeruginosa and S. quadricauda in co-cultured experiment with alanine nitrogen source. The error bars is standard deviation of Chlorophyll a

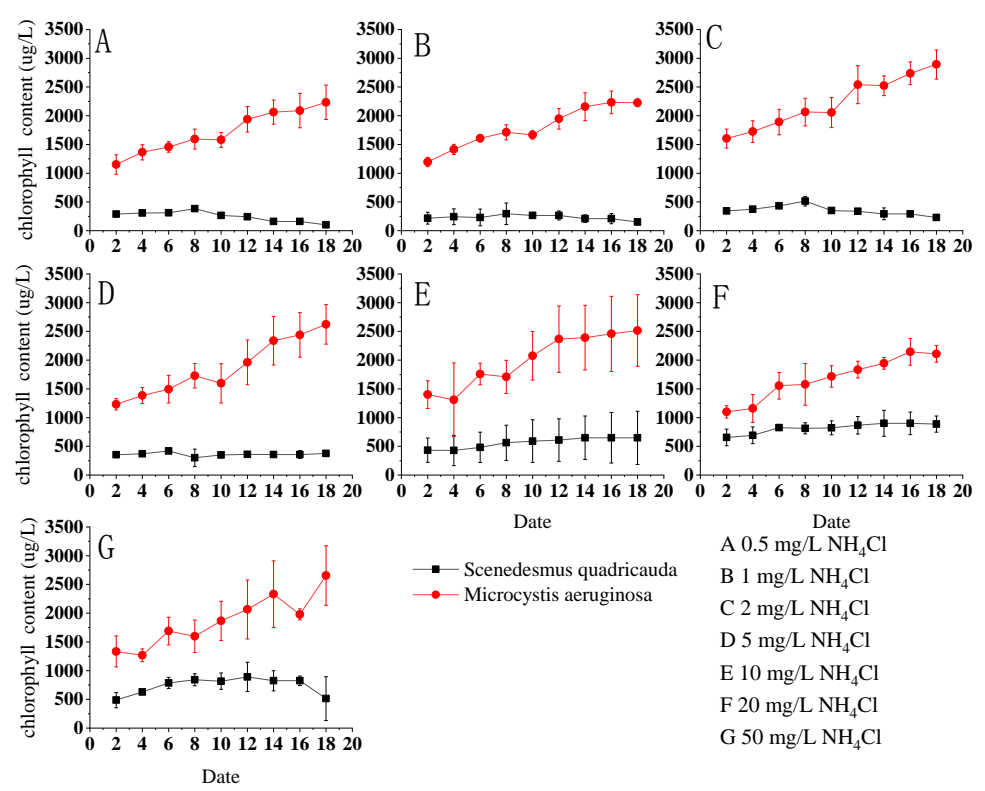

Figure 2. Chlorophyll a of M. aeruginosa and S. quadricauda in co-culture experiment with ammonium nitrogen source. The error bars are standard deviation of Chlorophyll a

\section{The chlorophyll a content of $M$. aeruginosa and $S$. quadricauda under two nitrogen sources in monoculture experiment}

Using alanine and ammonium as nitrogen sources, we cultured the S. quadricauda and $M$. aeruginosa respectively. The changing trend of chlorophyll $a$ of the two algae is shown in Figure 3. In the ammonium nitrogen treatment group (Figure 3A), the chlorophyll $a$ content of $M$. aeruginosa increased with time in the high concentration of $10,20,50 \mathrm{mg} / \mathrm{L}$ ammonium nitrogen treatment group, and the content was higher than 
that of other groups. In $0.5,1,2,5 \mathrm{mg} / \mathrm{L}$ low concentration ammonium nitrogen treatment groups, the content of chlorophyll $a$ of $M$. aeruginosa increased at the initial stage of culture, and decreased gradually after 11 days, which was lower than that of high concentration ammonium group. At the end of the culture period, the chlorophyll $a$ content of $M$. aeruginosa was $1.74,1.54,1.16 \mathrm{mg} / \mathrm{L}$ separately in $50,20,10 \mathrm{mg} / \mathrm{L}$ ammonium nitrogen group, which was $1.7,1.5$ and 1.3 times higher than that in the initial culture. The chlorophyll $a$ content of $M$. aeruginosa was $0.72,0.73,0.87,0.93 \mathrm{mg} / \mathrm{L}$ separately in $0.5,1,2,5 \mathrm{mg} / \mathrm{L}$ ammonium nitrogen group, which was slightly higher or lower than that in the initial culture. In the alanine treated group (Figure 3B), the chlorophyll $a$ content of $M$. aeruginosa decreased with the culture time, and the chlorophyll $a$ in each treated group was lower in the end of the experimental phase than that at the beginning phase. In the entire growth period, the M. aeruginosa's chlorophyll $a$ in $0.5,1,2 \mathrm{mg} / \mathrm{L}$ alanine group was higher than that of other high concentration groups. The results showed that the content of chlorophyll $a$ of $M$. aeruginosa in low alanine concentration group was higher than that in high concentration group, especially in $20 \mathrm{mg} / \mathrm{L}$ and $50 \mathrm{mg} / \mathrm{L}$ alanine group, the chlorophyll $a$ content of $M$. aeruginosa was lower than that of other treatment groups. Comparison of ammonium nitrogen and alanine treated groups, we discovered that the growth potential of $M$. aeruginosa increased with the high of the concentration of ammonium nitrogen, and the maximum growth potential happened in the treatment of $20 \mathrm{mg} / \mathrm{L}$ and $50 \mathrm{mg} / \mathrm{L}$ of ammonium nitrogen, but in the treatment of alanine, the growth trend of $M$. aeruginosa decreased with the increase of the concentration of alanine, which indicated that $M$. aeruginosa has better utilization of inorganic nitrogen than organic nitrogen.
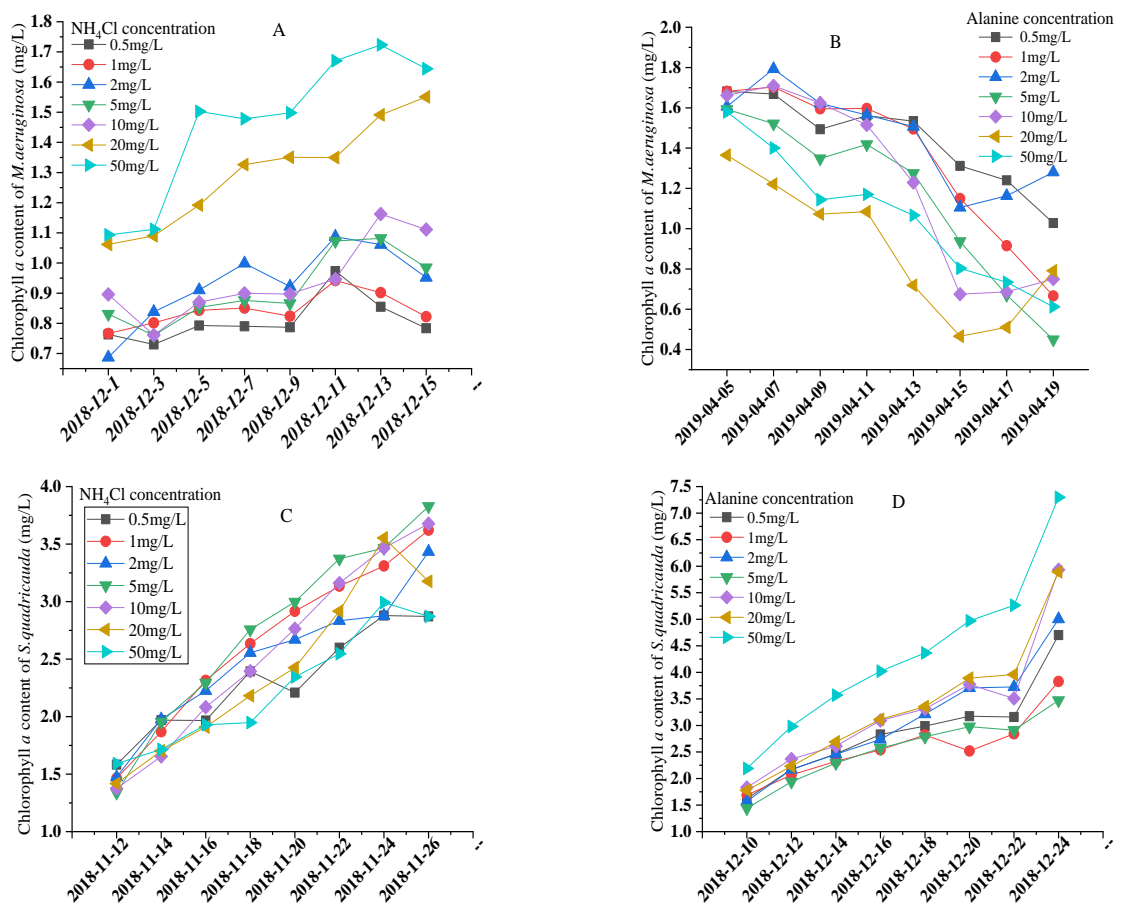

Figure 3. Chlorophyll a of in M. aeruginosa and S. quadricauda in monoculture experiment with ammonium and alanine separately. M. aeruginosa and $S$. quadricauda from the Freshwater Algae Culture Collection of the Institute of Hydrobiology (FACHB-collection, Wuhan, China) were cultured in medium in a light incubator for 2 months. Then these algaes were used in the experiment 
$S$. quadricauda was cultured respectively with alanine and ammonium as nitrogen sources (Figure 3C, D), chlorophyll a content is as follows, the growth of $S$. quadricauda was the highest in the treatment group of $5 \mathrm{mg} / \mathrm{L}$ and $10 \mathrm{mg} / \mathrm{L}$ concentration ammonium, that the chlorophyll $a$ increased nearly three times than that in the beginning phase. With the increase of ammonium concentration, the growth of $S$. quadricauda tended to decline. The growth potential of $S$. quadricauda in $1 \mathrm{mg} / \mathrm{L}$ and $5 \mathrm{mg} / \mathrm{L}$ alanine treatment group was the worst. In $50 \mathrm{mg} / \mathrm{L}$ alanine treatment group, the $S$. quadricauda's chlorophyll $a$ increased rapidly and reached to $7.3 \mathrm{mg} / \mathrm{L}$. Comparison to ammonium and alanine treated groups, we found that the chlorophyll $a$ of $S$. quadricauda (Figure $3 D$ ) in alanine treatment groups was higher than that in the corresponding concentration of ammonium treatment group, which indicated that organic nitrogen (alanine) is better than inorganic nitrogen (ammonium nitrogen) for the growth of $S$. quadricauda. At the end of experimental culture phase, chlorophyll $a$ of $S$. quadricauda was the same value of $2.87 \mathrm{mg} / \mathrm{L}$ in the treatment group of $0.5 \mathrm{mg} / \mathrm{L}$ and $50 \mathrm{mg} / \mathrm{L}$ ammonium nitrogen, which were the lowest among all the ammonium treatment groups. The S. quadricauda's chlorophyll $a$ was the highest in the treatment group of $5 \mathrm{mg} / \mathrm{L}$ and $10 \mathrm{mg} / \mathrm{L}$ ammonium, which indicated that $5-10 \mathrm{mg} / \mathrm{L}$ ammonium nitrogen was more suitable for the growth of $S$. quadricauda, and $0.5 \mathrm{mg} / \mathrm{L}$ extremely low concentration and $50 \mathrm{mg} / \mathrm{L}$ extremely high concentration ammonium did not benefit to $S$. quadricauda. In the alanine treatment group, chlorophyll $a$ of $S$. quadricauda was the highest in the extremely high concentration of alanine $50 \mathrm{mg} / \mathrm{L}$ and $20 \mathrm{mg} / \mathrm{L}$ treatment groups, which were $7.30 \mathrm{mg} / \mathrm{L}$ and $5.89 \mathrm{mg} / \mathrm{L}$, respectively, which indicated that $S$. quadricauda was more suitable for the high concentration of organic nitrogen.

\section{Comparison of photosynthetic activity of M. aeruginosa and S. quadricauda under two nitrogen sources}

The photosynthetic activity of $M$. aeruginosa in the treatment group of ammonium and alanine is shown in Figure 4. In the $50 \mathrm{mg} / \mathrm{L}$ ammonium group (Figure $4 A$ ), the average photosynthetic activity was 0.52 higher than that of other groups, which is the range of $0.47-0.60$ in the whole growth period. In the $0.50 \mathrm{mg} / \mathrm{L}$ ammonium group, its value was the lowest with the average value of 0.36 and the range of $0.23-0.46$. The photosynthetic activity of $M$. aeruginosa rose with the increase of ammonium concentration, indicating that $M$. aeruginosa grew strongly in the high concentration of ammonium. The average photosynthetic activity of $M$. aeruginosa in 10,20 , and $50 \mathrm{mg} / \mathrm{L}$ alanine treatment groups (Figure $4 B$ ) were the highest, with values of $0.49,0.52$ and 0.53 , and the range value of $0.31-0.62,0.49-0.61$ and $0.47-0.60$, respectively. The average photosynthetic activity of $M$. aeruginosa in the ammonium group was higher than that in the same alanine concentration group, showing that the growth potential of $M$. aeruginosa in ammonium nitrogen was higher than that in alanine organic nitrogen.

For $S$. quadricauda (Figure $4 C, D$ ), the mean photosynthetic activity was the highest ( 0.74 and 0.75 , respectively) in the $5 \mathrm{mg} / \mathrm{L}$ and $10 \mathrm{mg} / \mathrm{L}$ ammonium treatment group, and the range of values was 0.68-0.80 and 0.66-0.87, respectively, the lower value appeared in the $0.5 \mathrm{mg} / \mathrm{L}, 1 \mathrm{mg} / \mathrm{L}$ and $50 \mathrm{mg} / \mathrm{L}$ ammonium group, which indicated that the photosynthetic activity of $S$. quadricauda was very low in very low and high concentration of ammonium nitrogen and the photosynthetic activity of $S$. quadricauda was strong in the medium concentration of ammonium nitrogen. Among the alanine treatment groups (see Figure 4D), the highest average photosynthetic activity of S. quadricauda was found in $20 \mathrm{mg} / \mathrm{L}$ and $50 \mathrm{mg} / \mathrm{L}$ alanine treatment group with the 
identical mean values of 0.75 and the range value with $0.66-0.87$ and $0.67-0.81$, respectively, and these values were higher than that in the corresponding same concentration ammonium treatment group, which indicated that the growth potential of S. quadricauda in the high concentration of alanine was higher than that in the high concentration of ammonium.
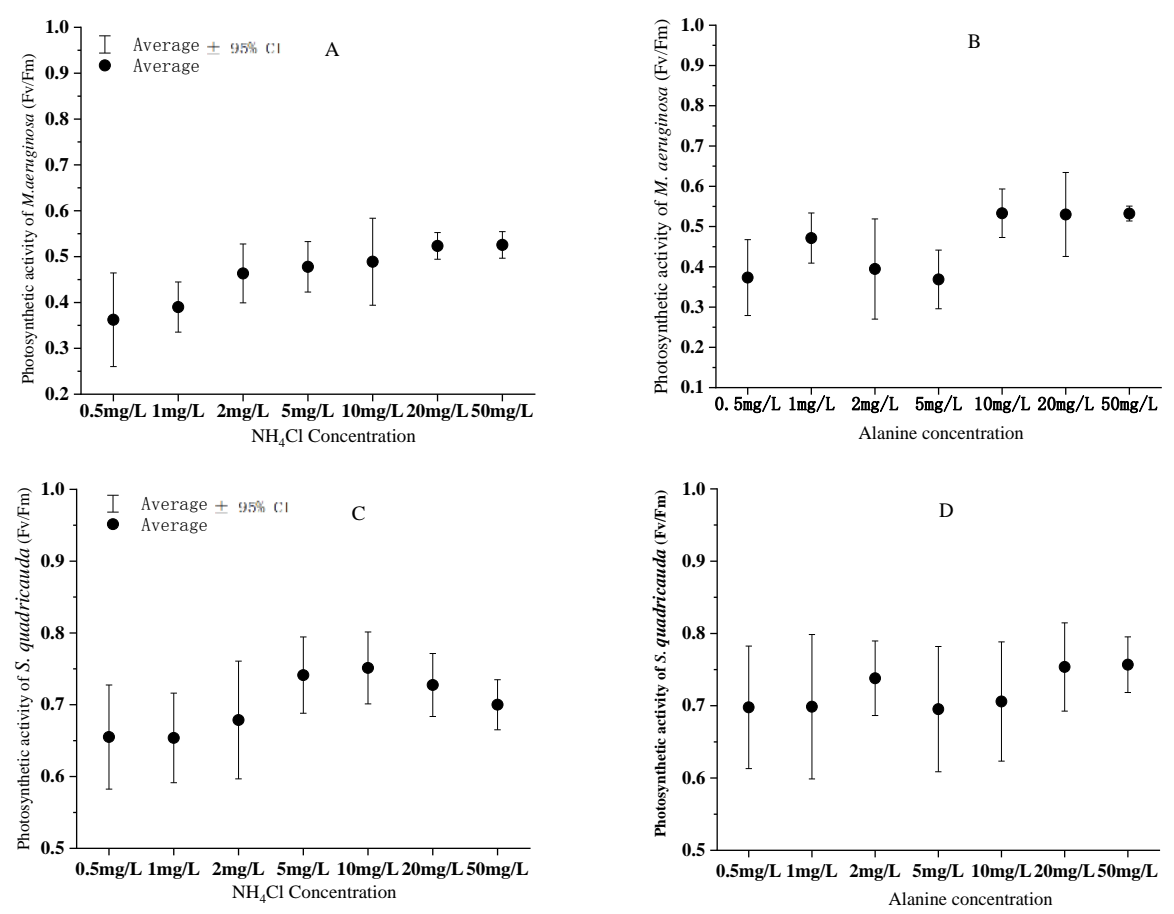

Figure 4. The photosynthetic activities of M. aeruginosa and S. quadricauda under different nitrogen sources. These values were measured every 2 days during the 18-day culture cycle

\section{The maximum photosynthetic rate difference of $M$. aeruginosa and $S$. quadricauda in monoculture under two nitrogen sources}

Phyto PAM was used to determine the rapid light response curve of $M$. aeruginosa and $S$. quadricauda under the separate cultivation of two nitrogen sources. The characteristic parameter of the maximum electron transport rate (ETRmax) is to characterize the photosynthesis efficiency of phytoplankton, and the data is shown in Figure 5. In the high of ammonium concentration such as 10,20,50 mg/L treatment group (in Figure 5A), the highest variation of ETRmax value of $M$. aeruginosa was found in the whole culture period. After 9 days, the ETRmax of $M$. aeruginosa in the $50 \mathrm{mg} / \mathrm{L}$ ammonium group increased gradually, which was higher than that in the other concentration group. And its value of $M$. aeruginosa in $10,20 \mathrm{mg} / \mathrm{L}$ ammonium treatment group increased in the initial period, and then decreased after 9 days. In the alanine treatment group (see Figure 5B), the ETRmax of $M$. aeruginosa in the high concentration $10,20,50 \mathrm{mg} / \mathrm{L}$ treatment group was higher than that of the low concentration treatment, and increased gradually with the culture time, reaching the maximum value at $15^{\text {th }}$ day, and then decreased gradually. At the end of the experiment, the ETRmax of $M$. aeruginosa in $50 \mathrm{mg} / \mathrm{L}$ alanine group is the highest, followed by $20 \mathrm{mg} / \mathrm{L}$ alanine treatment group. 


$$
\text { - } 1615 \text { - }
$$
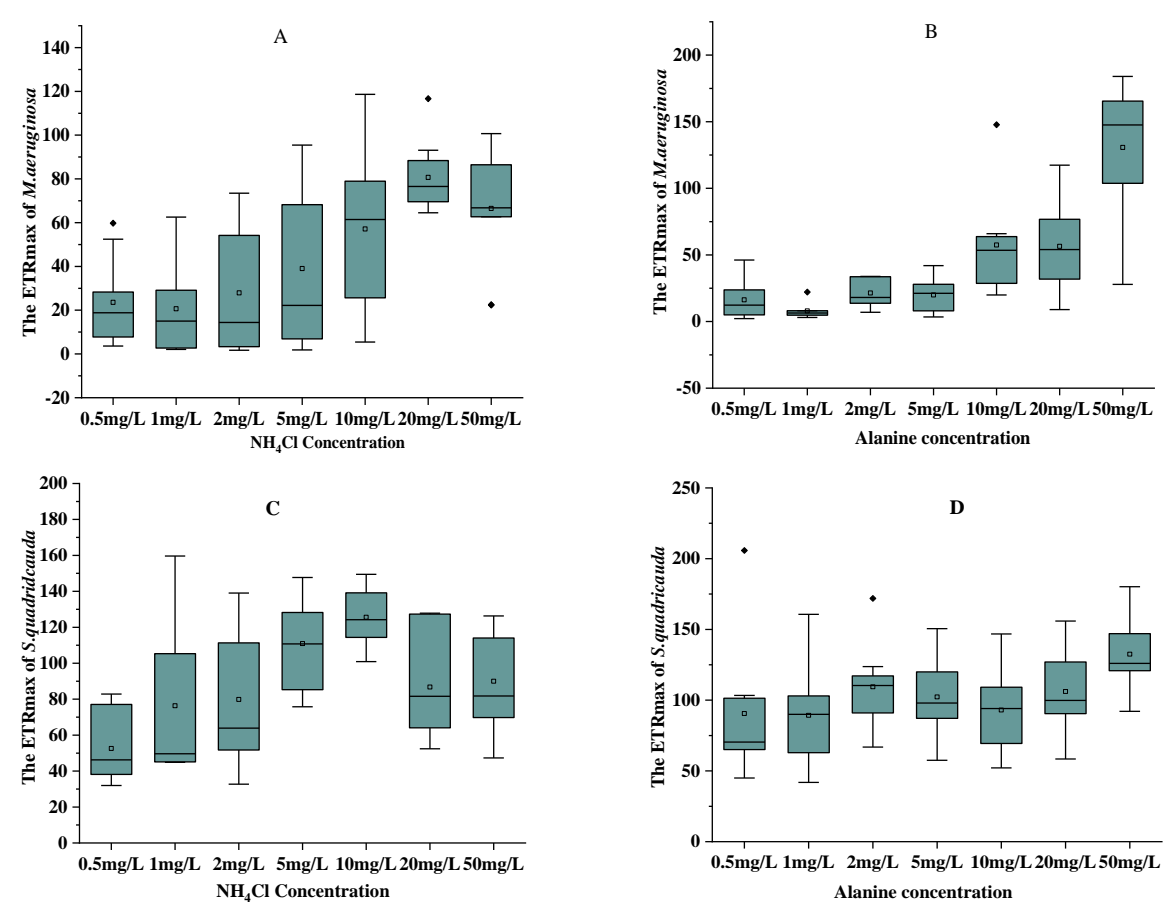

Figure 5. The ETRmax of M. aeruginosa and S. quadricauda under different nitrogen sources. These values were measured every 2 days during the 18-day culture cycle

The ETRmax of $S$. quadricauda treated with ammonium and alanine is as following. In the ammonium treatment group (Figure 5C), except for the $10 \mathrm{mg} / \mathrm{L}$ treatment group, the ETRmax of $S$. quadricauda in the other ammonium treatment groups decreased with the culture time in the growth period. The ETRmax of $S$. quadricauda in the $10 \mathrm{mg} / \mathrm{L}$ and $5 \mathrm{mg} / \mathrm{L}$ ammonium groups (see Figure $5 C$ ) was higher than that in the other groups, while that value in the low concentration ammonium $(0.5 \mathrm{mg} / \mathrm{L}$ and $1 \mathrm{mg} / \mathrm{L})$ treatment group was the lowest. In the alanine treatment group (Figure 5D), the ETRmax of S. quadricauda in the $50 \mathrm{mg} / \mathrm{L}$ group was higher than that in the other groups, and this value in the low concentration alanine group $(0.5 \mathrm{mg} / \mathrm{L}$ and $1 \mathrm{mg} / \mathrm{L})$ was the lowest.

\section{The difference of saturated light intensity $\left(I_{k}\right)$ between $M$. aeruginosa and S. quadricauda under two nitrogen sources}

The saturated light intensity $\left(\mathrm{I}_{\mathrm{k}}\right)$ indicates the adaptability of phytoplankton to light intensity. The $\mathrm{I}_{\mathrm{k}}$ values of $M$. aeruginosa and $S$. quadricauda under the monoculture of two nitrogen sources are shown in Figure 6. The median value of $\mathrm{I}_{\mathrm{k}}$ of M. aeruginosa in the two nitrogen source treatments grew with the increase of nitrogen concentration (see Figure $6 A, B$ ), which showed that $M$. aeruginosa had stronger adaptability to strong light if it was cultured in the high concentration of alanine and ammonium nitrogen. The variation ranges of $\mathrm{I}_{\mathrm{k}}$ of $M$. aeruginosa in the high concentration of alanine group were wide, while in the high concentration of ammonium nitrogen group the variation of this was small. Among the ammonium treatment groups (Figure $6 C$ ), the median value of $\mathrm{I}_{\mathrm{k}}$ of $S$. quadricauda was the lowest in the $0.5 \mathrm{mg} / \mathrm{L}$ ammonium group, and the $\mathrm{I}_{\mathrm{k}}$ of $S$. quadricauda in $20 \mathrm{mg} / \mathrm{L}$ and $50 \mathrm{mg} / \mathrm{L}$ treatment groups was only higher than that in $0.5 \mathrm{mg} / \mathrm{L}$ ammonium treatment group, but lower than that in other treatment groups, and the fluctuation range was large. 


$$
\text { - } 1616 \text { - }
$$
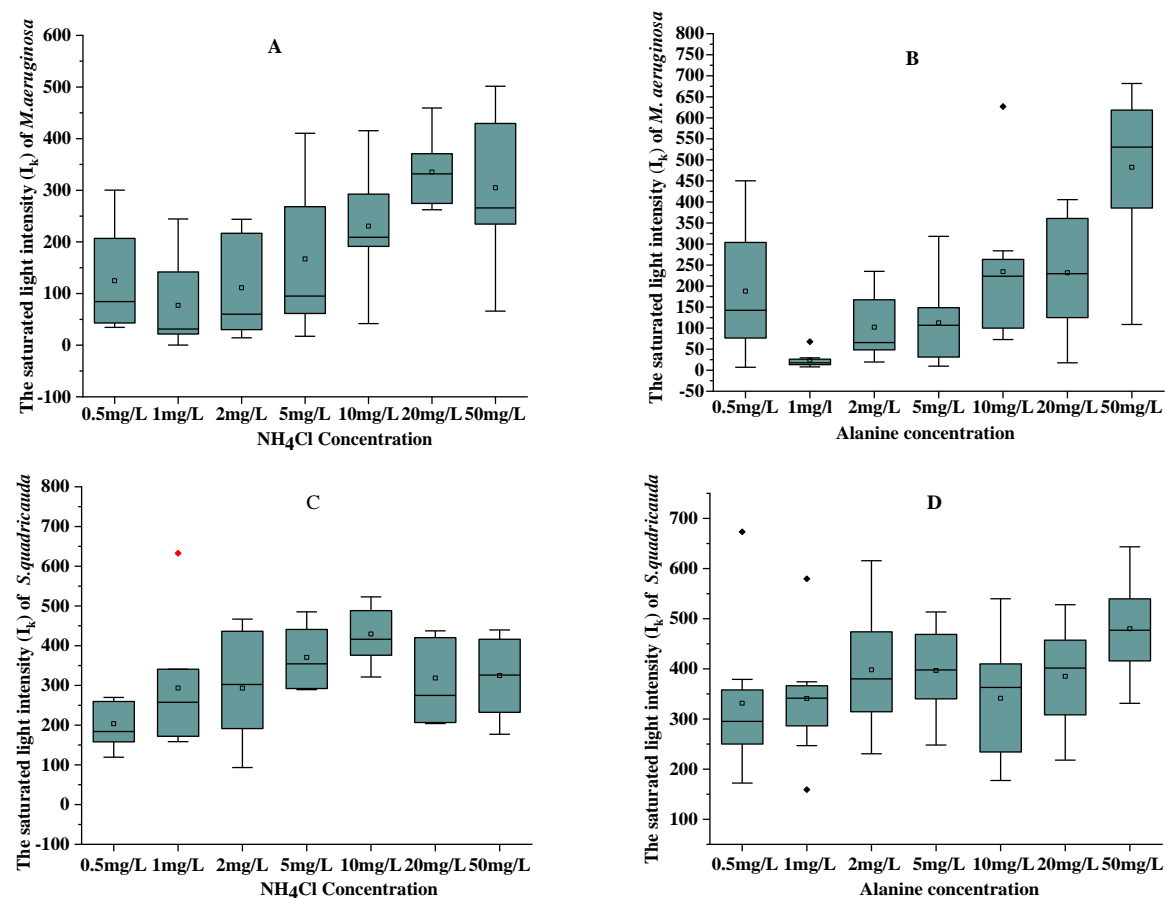

Figure 6. The saturated light intensity $\left(I_{k}\right)$ of M. aeruginosa and S. quadricauda under different nitrogen sources. These values were measured every 2 days during the 18-day culture cycle

The $\mathrm{I}_{\mathrm{k}}$ of $S$. quadricauda increased gradually in the alanine treatment group (Figure $6 D$ ), and the median $\mathrm{I}_{\mathrm{k}}$ of $S$. quadricauda in $50 \mathrm{mg} / \mathrm{L}$ alanine treatment was the highest, and the fluctuation range of this value was very small, which indicated that the high concentration of alanine was better than the low concentration group. The ability of $S$. quadricauda in high concentration of alanine treatment to resist strong light was stronger than that in the low concentration group. In the high concentration $(20 \mathrm{mg} / \mathrm{L}$ and $50 \mathrm{mg} / \mathrm{L})$ and low concentration $(0.5 \mathrm{mg} / \mathrm{L}$ and $1 \mathrm{mg} / \mathrm{L})$ of alanine treatment group (Figure $6 D$ ), the saturation light intensity $\left(\mathrm{I}_{\mathrm{k}}\right)$ of $S$. quadricauda was higher than that of the corresponding concentration of ammonium nitrogen treatment group, which indicated that the tolerance of $S$. quadricauda to strong light in organic nitrogen source was higher than that of inorganic nitrogen source.

\section{The cell morphology of M. aeruginosa and S. quadricauda under two nitrogen sources}

The plastid morphology of $S$. quadricauda under monoculture of two nitrogen sources is shown in Figure 7. In the ammonium treatment, $S$. quadricauda is mainly composed of two cells and four cells, and these cells were suffered seriously with the higher concentration of ammonium nitrogen. In the alanine experimental group, the content of chlorophyll of $S$. quadricauda was higher and the complete the plastid morphology was cell integrity with the increasing concentration of alanine, which indicated alanine benefited to maintain plastid integrity of $S$. quadricauda. 


$$
\text { - } 1617 \text { - }
$$
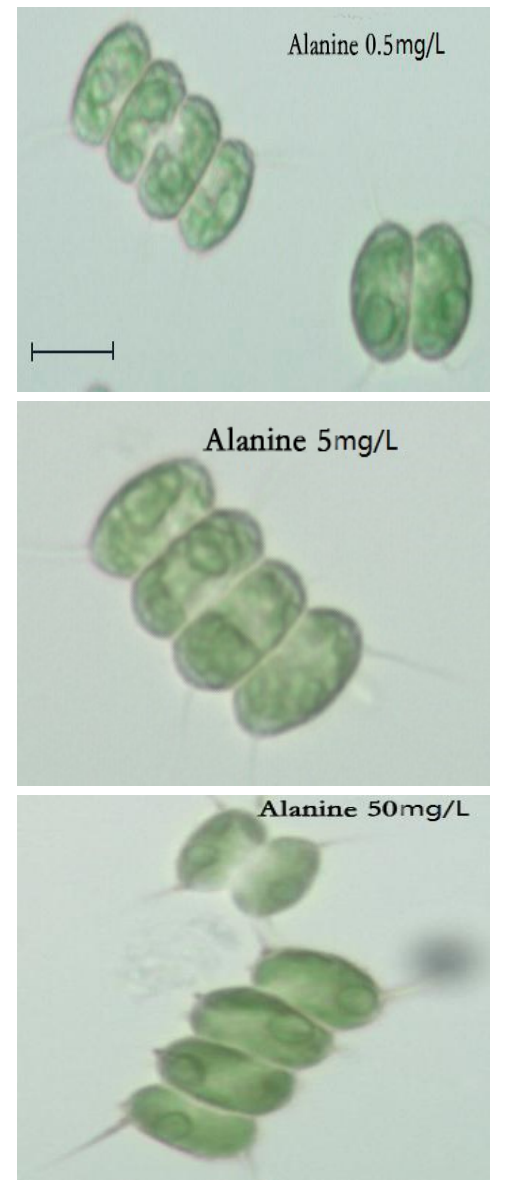

Ammonium nitrogen $2 \mathrm{mg} / \mathrm{L}$

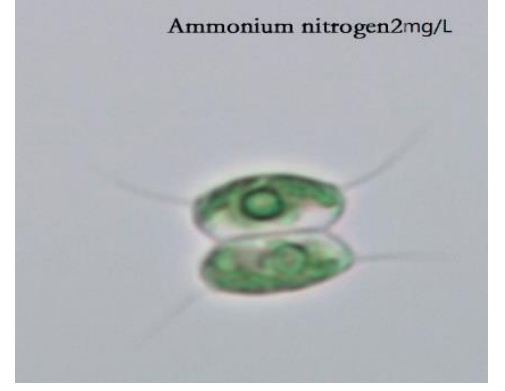

Ammonium nitrogen20mg/L

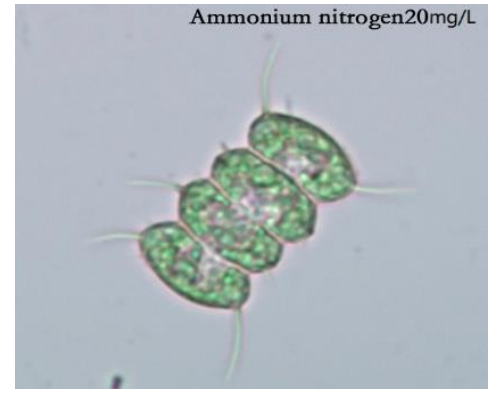

Figure 7. Cells of S. quadricauda. Scale bars indicate $10 \mu \mathrm{m}$
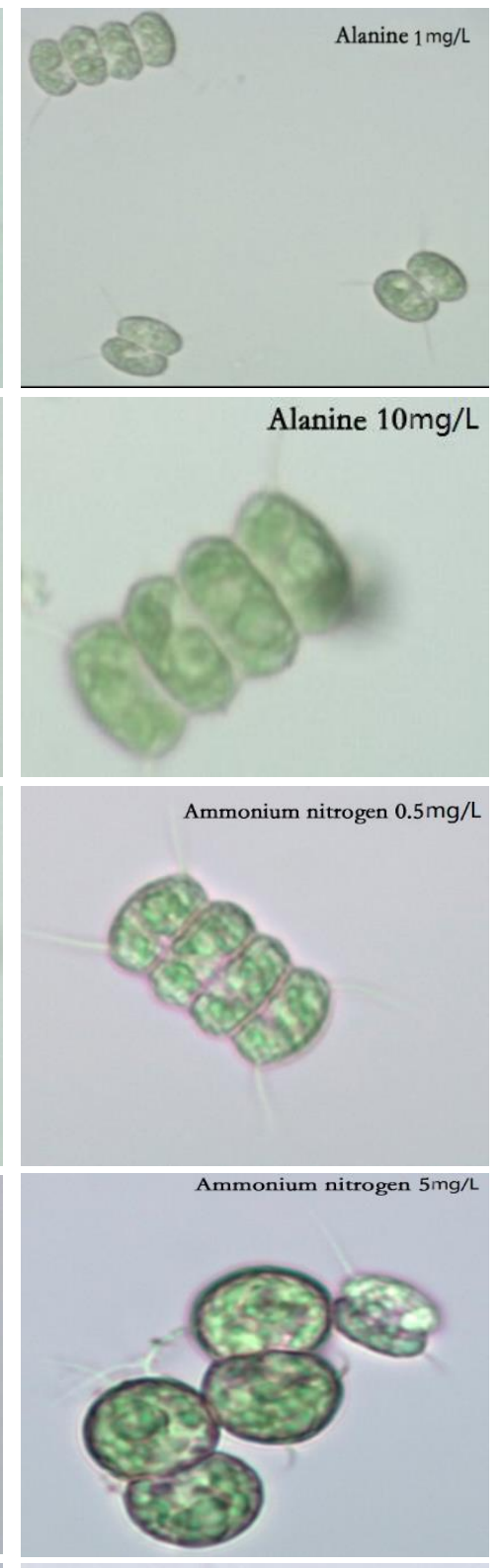

Ammonium nitrogen $50 \mathrm{mg} / \mathrm{L}$

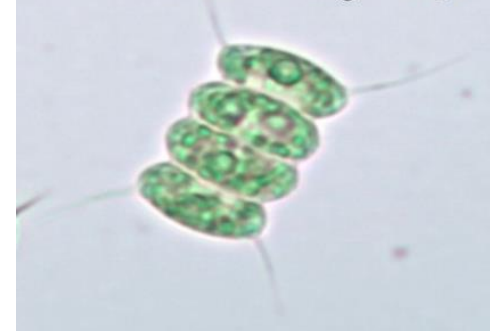

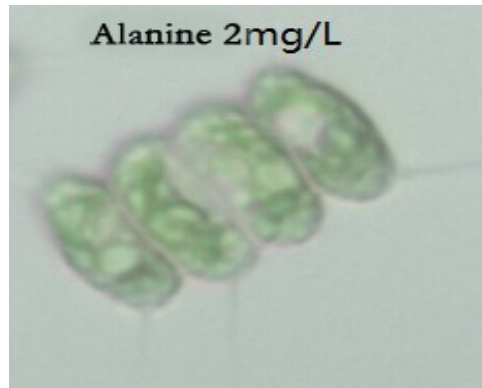
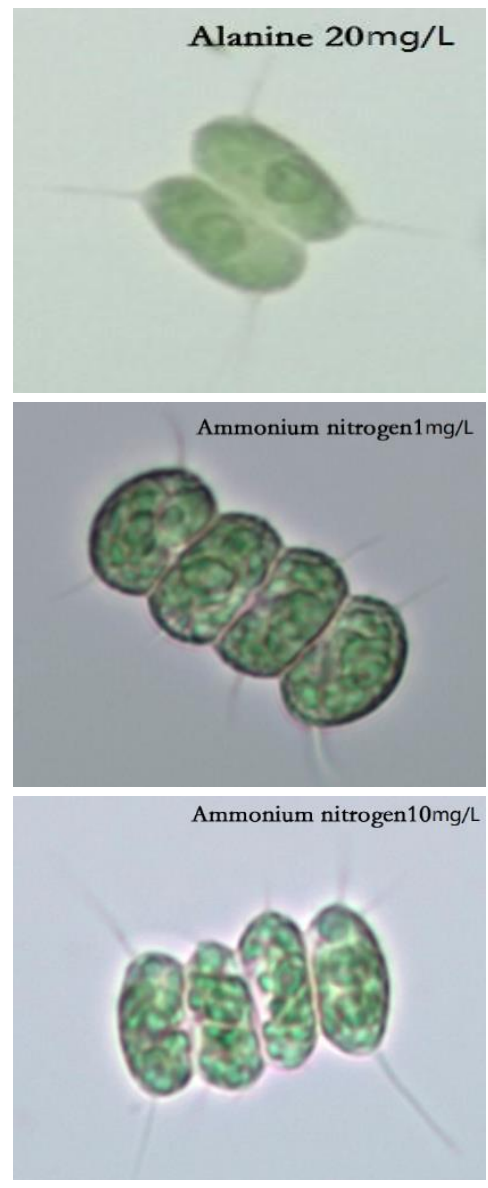
reduction. In the alanine group, the $M$. aeruginosa cells in the $0.5-5 \mathrm{mg} / \mathrm{L}$ concentration treatment group remained intact. When the alanine concentration was more than $10 \mathrm{mg} / \mathrm{L}$, the damage of $M$. aeruginosa cells was more and more serious. It can be seen from the figure that the plastid of $M$. aeruginosa can tolerate a high concentration of inorganic nitrogen, while it suffered more serious in high concentration of organic nitrogen.
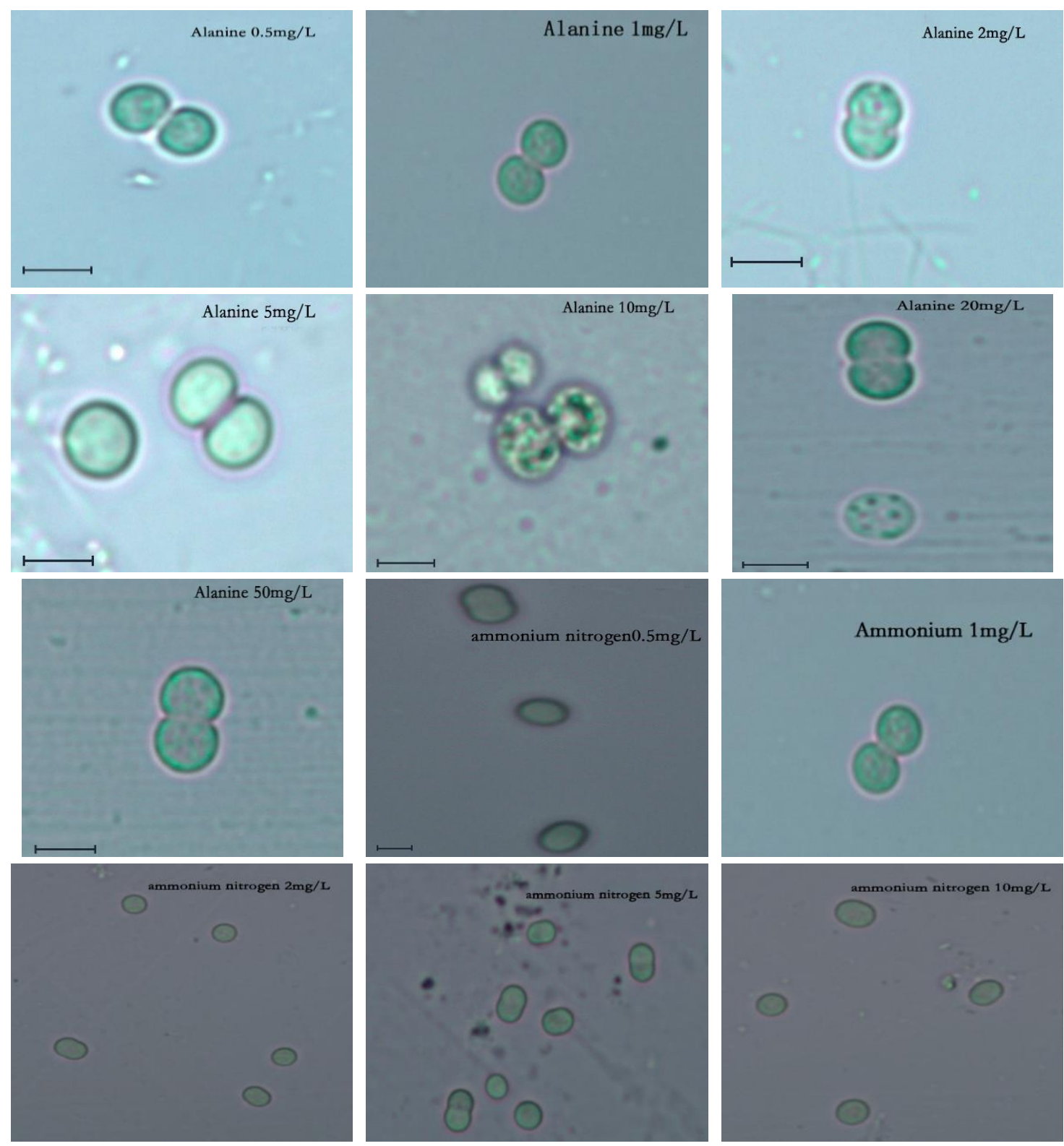

ammonium nitrogen $20 \mathrm{mg} / \mathrm{L}$

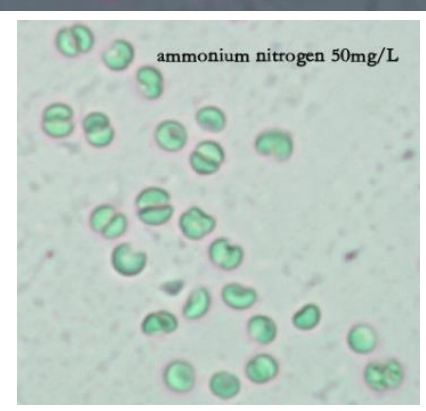

Figure 8. Cells of M. aeruginosa. Scale bars indicate $10 \mu \mathrm{m}$ 


\section{Discussion}

\section{Effect of different nitrogen on the growth of M. aeruginosa and S. quadricauda}

From Figure 1 and Figure 2, M. aeruginosa have a strong advantage in the utilization of ammonium, while $S$. quadricauda has a strong advantage in the utilization of alanine in the co-culture experiment. Because $M$. aeruginosa is a unicellular algae, it is generally believed that the utilization ability of unicellular algae to reduced ammonium salt $\left(\mathrm{NH}_{4} \mathrm{Cl}\right)$ is better than other nitrogen forms (Muro-Pastor and Florencio, 2003). This is mainly due to other nitrogen sources needing to be reduced to ammonia by nitrate reductase and nitrite reductase before these nutrients can be used. This reduction pressure forces $M$. aeruginosa to face the energy consumption for photosynthesis (Michard et al., 1996; Giani and Delgado, 1998; Meng et al., 2015). It is generally believed that alanine, as a small molecule organic compound, can not only enter cells through passive diffusion, but also enter cells through active transport. Moreover, $M$. aeruginosa, in the alanine treatment group, decreased with culture period (see Figure 3), which shows that not all phytoplankton can use organic nitrogen sources efficiently. Since $M$. aeruginosa effectively prefers to utilize ammonium nitrogen, we should pay attention to the role of microorganisms in promoting $M$. aeruginosa to become the dominant species through ammonization in lake. At present, the main management measure of eutrophic water body is to reduce the input of total nitrogen. However, Wu et al. (2013) pointed out that microbial community structure is very important for the change of available nitrogen sources into different forms. So algae control should not only be limited to the control of total nitrogen, but also focus on reducing the input of various nitrogen sources due to the ammonification of microorganisms.

Different algae species have different abilities to utilize different forms of nitrogen. Compared with $M$. aeruginosa, $S$. quadricauda, as multicellular algae, needs more nitrogen to maintain cell proliferation. Each cell of $S$. quadricauda has a peripheral and protein nucleus (Hu and Wei, 2006), and light energy is converted into chemical energy depending on the photosynthetic pigment in these melanosomes (Yan et al., 2012; Chandler et al., 2014). In this study, with the increase of $\mathrm{NH}_{4}{ }^{+}-\mathrm{N}$ concentration (see Figure 7), the degree of damage on melanosomes in S. quadricauda increased gradually, which directly affected its photosynthetic efficiency. However, when alanine was used as the nitrogen source, melanosomes of $S$. quadricauda were in good condition as the alanine concentration increased. Therefore, whether cultured alone or together with $M$. aeruginosa, the growth potential of $S$. quadricauda is better with alanine nitrogen than that of ammonium nitrogen, and it has better utilization advantages with alanine nitrogen than that of ammonium nitrogen. Hou et al. (2018) studied the relationship between phytoplankton succession and nutrients in Dianchi Lake and found that $S$. quadricauda was the main dominant species in the north of Dianchi Lake (Caohai Bay) with high total nitrogen and phosphorus in Caohai Bay, and M. aeruginosa is the dominant species in the south of Dianchi Lake (Waihai lake). This phenomenon is because that the Caohai Bay mainly receives the treated municipal wastewater with the higher organic matter while Waihai lake receives its main nitrogen source from agricultural non-point source pollution. Therefore, in the same period, $S$. quadricauda has a strong advantage in the utilization of organic nitrogen and developed into the dominant species in Caohai Bay, while $M$. aeruginosa is the dominant species in Waihai lake. In this study, it was found that in both ammonium and alanine nitrogen sources, S. quadricauda forms four-cell morphological algae structures that are sensitive to settle in water. This is conducive to 
the growth of submerged plants and their strong competition for light and nutrition (Wang et al., 2009; Dong et al., 2013; Yang et al., 2015).

Different algae species not only have a distinguishable ability to use a variety of forms of nitrogen, but also have different requirements for nitrogen concentration for its growth. In our study, high concentrations of ammonium nitrogen $(>20 \mathrm{mg} / \mathrm{L})$ in the 16 days' culture period were beneficial to $M$. aeruginosa by increasing chlorophyll $a$ content. This result did not coincide with reports which state high concentrations of $\mathrm{NH}_{4}{ }^{+}-\mathrm{N}$ can produce toxic effects on $M$. aeruginosa and affect the normal algae growth (Azov and Goldman, 1982; Zhou et al., 2013). M. aeruginosa's chlorophyll $a$ in the stress of high concentrations of ammonium chloride is to lag, so that the toxic effect of high concentrations of ammonium chloride is not obvious in the 16 days' culture cycle. However, other studies suggested that the growth of $M$. aeruginosa is limited when the ammonium nitrogen concentration reaches $50 \mathrm{mg} / \mathrm{L}$ (Dai et al., 2017). As autotrophs for photosynthesis, the photosynthetic activity of $M$. aeruginosa is directly related to the growth potential. When the ammonium nitrogen concentration is high ( $>10 \mathrm{mg} / \mathrm{L})$, the photosynthetic activity $\mathrm{Fv} / \mathrm{Fm}$ of $M$. aeruginosa is constantly rising, and higher than that of the low concentration of ammonium treatment group (see Figure 4). In terms of cell morphology of $M$. aeruginosa, when the ammonium nitrogen concentration is 0.5 $20 \mathrm{mg} / \mathrm{L}$, plastids remain intact. When the ammonium nitrogen concentration reaches $50 \mathrm{mg} / \mathrm{L}$, the chlorophyll in the plastids of $M$. aeruginosa show slight damage. These results showed that $M$. aeruginosa prefers high concentrations of ammonium nitrogen because it can maintain high photosynthetic activity with sound plastid structure in ammonium nitrogen water. some other research shows that there is no significant difference in the absorption of urea (organic nitrogen) and ammonium chloride by $M$. aeruginosa, and the absorption of these nitrogen forms by $M$. aeruginosa was significantly higher than that of nitrate-nitrogen (Xu et al., 2019). However, our study found that the chlorophyll $a$ of $M$. aeruginosa in the high concentration of alanine nitrogen (> $20 \mathrm{mg} / \mathrm{L}$, organic nitrogen) was lower than that of other concentrations of alanine, and declined sharply as the culture time passed (see Figure 3). This indicated that not all small organic molecular forms of nitrogen can effectively promote $M$. aeruginosa growth. Alanine $\left(\mathrm{CH}_{3} \mathrm{CH}\left(\mathrm{NH}_{2}\right) \mathrm{COOH}\right)$ is a carboxyl compound and an acidic amino acid, and the $\mathrm{pH}$ value of the alanine culture medium is unfavorable to the $\mathrm{pH}$ environment required for the growth of $M$. aeruginosa. In the growth process, $M$. aeruginosa absorbs $\mathrm{CO}_{2}$ and $\mathrm{HCO}_{3}^{-}$, through photosynthesis, and removes $\mathrm{H}^{+}$in the culture medium increasing the $\mathrm{pH}$ value. The high $\mathrm{pH}$ environment rapidly accelerates the growth of $M$. aeruginosa (Yu et al., 2016; Zhu et al., 2018).

\section{Effects of different nitrogen on Photosynthetic Physiological Characteristics of $M$. aeruginosa and S. quadricauda}

One of the fundamental indexes reflecting the potential maximum photosynthetic capacity (photosynthetic efficiency) is the maximum conversion efficiency ( $\mathrm{Fv} / \mathrm{Fm}$ ) of PS II which is the ratio of the maximum variable fluorescence to the total fluorescence. The measurement of $\mathrm{Fv} / \mathrm{Fm}$ is often applied as a conventional means to investigate the response of algae to the environment because this parameter will decrease if algae is stressed by alien species or detrimental growth conditions (Björkman and Demmig, 1987; Krause, 1988; Xu et al., 1992; Han et al., 2005; Liu et al., 2019). The growth potential of algae in fresh water increases as photosynthetic activity increases, so the possibility of algae becoming the dominant species rises. In this experiment, the photosynthetic activity 
(Fv/Fm) of $M$. aeruginosa was enhanced as the level of ammonium concentration increased, and the chlorophyll $a$ increased correspondingly, which indicated that there was a certain positive correlation between the photosynthetic activity and biomass. With an increase of ammonium concentration, M. aeruginosa had higher photosynthetic activity and grew rapidly. $M$. aeruginosa had low Fv/Fm in $0.5 \mathrm{mg} / \mathrm{L}$ and $1 \mathrm{mg} / \mathrm{L}$ ammonium culture medium, and its growth potential was weakened, which may be the result of insufficient nutrients (Young and Beardall, 2003). Although chlorophyll $a$ content of $M$. aeruginosa declined sharply with of the higher alanine concentration, the $\mathrm{Fv} / \mathrm{Fm}$ of $M$. aeruginosa went up to the high value in the high alanine concentration (> $20 \mathrm{mg} / \mathrm{L}$ ) culture medium, which may be because the high concentration of alanine did not cause any stress on the light energy conversion rate of $M$. aeruginosa, and it was not necessary to change the parameter Fv/Fm of photosynthetic activity to adapt to the high concentration of alanine environment (Wang, 2018). For S. quadricauda, the Fv/Fm in the high concentration ammonium culture medium (> $20 \mathrm{mg} / \mathrm{L}$ ) was lower than that of the same concentration alanine treatment group, which suggested that the photochemical activity of PSII in S. quadricauda may be destroyed, and the photosynthetic electron transfer may be blocked under the stress of high concentrations of ammonium nitrogen. It is generally believed that Fv/Fm will be significantly reduced under the stress of high ammonium nitrogen or low ammonium nitrogen, which will lead to the decrease of biomass and chlorophyll fluorescence parameters (Young and Beardall, 2003). Most of the plastid of $S$. quadricauda are absent due to high concentrations of non-protonation ammonium nitrogen inhibiting photosynthetic activity (Dai et al., 2017). In this study, the plastid structure of $S$. quadricauda was damaged in the ammonium nitrogen culture medium, and the photosynthetic pigments in cells that convert light energy into stable chemical energy were also damaged hindering the process of photosynthetic electron transfer (Yang et al., 2015). It is a physiological reaction process for S. quadricauda to adapt to the stress of nutrients through the down regulation of photosynthesis (Lin et al., 1997). However, in the alanine nitrogen culture medium, Fv/Fm of $S$. quadricauda increased with the higher alanine concentration. As a small molecular amino acid, alanine can be absorbed into the cell by the way of active transport. The protein on the cell wall functions as a carrier, accelerating the rate of alanine entering the cell (Fang et al., 2013). Therefore, the growth potential of $S$. quadricauda in organic nitrogen water body is stronger than inorganic nitrogen water.

The higher the maximum photosynthetic rate (ETRmax) indicates that algae are less susceptible to photo inhibition under strong light conditions, and the smaller the ETRmax value indicates that the electron transfer is limited. The saturated light intensity $\left(\mathrm{I}_{\mathrm{k}}\right)$ is adaptable in algae to compensate strong light stress. Whether $M$. aeruginosa was cultured in alanine alone or in ammonium alone, M. aeruginosa had a higher maximum photosynthetic rate (ETRmax) and a higher $\mathrm{I}_{\mathrm{k}}$ as the nitrogen source concentration increased in each culture. This showed that these photosynthetic parameters of $M$. aeruginosa were not sensitive to different nitrogen sources. The actual photosynthetic capacity of $M$. aeruginosa was not affected by the variety of nitrogen sources, and this undoubtedly increased the ecological range of $M$. aeruginosa to adapt to nitrogen, and also improved its survival probability and competitiveness. Some scholars suggested that temperature and light intensity were the main factors affecting the photosynthetic activity of algae rather than the chemical form of nutrients, finding that the ETRmax value of some algae decreased significantly under 12800 lx light intensity (Zang et al., 2015). The change of $\mathrm{Fv} / \mathrm{Fm}$, ETRmax and $\mathrm{I}_{\mathrm{k}}$ values in both ammonium and alanine nitrogen groups 
was similar to that of chlorophyll $a$ in $S$. quadricauda, indicating that there was no need for $S$. quadricauda to increase these parameters to adapt to the changes in ammonium nitrogen and alanine concentration gradients, while the other view was that under the stress of high ammonium nitrogen or nitrogen limitation, some chlorophyll fluorescence parameters of algae would increase to adapt to the changing living environment (Wang et al., 2012), the mechanism needs to be further explored.

\section{Conclusion}

$M$. aeruginosa and $S$. quadricauda have strong advantage in the utilization of ammonium and alanine, respectively. The chlorophyll $a$ and the photosynthetic activity $\mathrm{Fv} / \mathrm{Fm}$ of $M$. aeruginosa is constantly rising in high concentrations of ammonium nitrogen (> $20 \mathrm{mg} / \mathrm{L})$. Whether $M$. aeruginosa was cultured in alanine alone or in ammonium alone, $M$. aeruginosa had a higher maximum photosynthetic rate (ETRmax) and the higher saturated light intensity $\left(\mathrm{I}_{\mathrm{k}}\right)$, indicating that these parameters of $M$. aeruginosa were not sensitive to different nitrogen sources and that this undoubtedly increased the ecological range of $M$. aeruginosa to adapt to nitrogen, and also improved its survival probability and competitiveness. For S. quadricauda, the plastid structure was damaged in the ammonium nitrogen culture medium, and the photosynthetic pigments in cells that convert light energy into stable chemical energy were also damaged hindering the process of photosynthetic electron transfer. Then the Fv/Fm of $S$. quadricauda was lower than that of the same concentration alanine treatment group.

Acknowledgments. This work was supported by special project of Basic Research in Yunnan Local Colleges and Universities (2017FH001-026, 2018FH001-004), the National Natural Science Foundation of China (31300349), and Scientific and Technological Innovation team Project of Agricultural Resources Utilization of Kunming University.

\section{REFERENCES}

[1] Azov, Y., Goldman, J. C. (1982): Free ammonia inhibition of algal photosynthesis in intensive cultures. - Applied and Environmental Microbiology 43(4): 735-739.

[2] Björkman, O., Demmig, B. (1987): Photon yield of $\mathrm{O}_{2}$ evolution and chlorophyll fluorescence characteristics at $77 \mathrm{~K}$ among vascular plants of diverse origins. - Planta 170(4): 489-504.

[3] Chandler, D. E., Strümpfer, J., Sener, M. (2014): Light harvesting by lamellar chromatophores in Rhodospirillum photometricum. - Biophysical Journal 106: 2503-2510.

[4] Conley, D. J., Paerl, H. W., Howarth, R. W. (2009): Ecology. Controlling eutrophication: nitrogen and phosphorus. - Science 323(5917): 1014-1015.

[5] Dai, L. L., Li, L., Zhou, W. C., Li, G. B. (2017): Response of Microcystis aeruginosa and tetrachystiella to ammonium nitrogen. - Biophysical Journal 36(8): 2289-2295.

[6] Dong, J., Lu, J. J., Li, G. B. (2013): Influences of a submerged macrophyte on colony formation and growth of a green alga. - Aquatic Biology 19: 265-274.

[7] Fang, L., Liu, W. Q., Zhao, N. J. (2013): The influence of Scenedesmus quadricanda on MC-LR producing, releasing and photosynthetic activity of Microcystis aeruginosa. Journal of Biology 30(3): 33-37.

[8] Geider, R. G., Roche, J. L., Greene, R. M. (1993): Response of the photosynthetic apparatus of Phaeodactylum tricornutum (Bacillariophyceae) to nitrate, phosphate, or iron starvation. - Journal of Phycology 29: 755-766. 
[9] Genty, B., Briantais, J. M., Baker, N. R. (1989): The relationship between the quantum yield of photosynthetic electron transport and quenching of chlorophyll fluorescence. Biochimica et Biophysica Acta (BBA), General Subjects 990(1): 87-92.

[10] Giani, A., Delgado, P. C. S. (1998): Growth dynamics and competitive ability of green (Oocystis lacustris) and a blue-green alga (Synechocystis sp.) under different N: P ratios. - Verhein der Internationalen Vereinigung von Limnologie 26: 1693-1697.

[11] Guo, L. L., Zhou, W. C., Zhou, Q. C. (2015): Effects of light intensity and phosphorus concentration on the growth of oligocladose setae. - Environmental Science in China 35(7): 2153-2159.

[12] Han, Z. G., Lei, L. M., Han, B. P. (2005): In situ monitoring of chlorophyll fluorescence using PAM fluorometer. - Ecological Science 23(03): 246-249.

[13] Hou, X. L., Yuan, C. G., Li, X. P. (2018): Effects of nitrogen and phosphorus concentration on interannual variation of blue, green and diatom in lake Dianchi. - Journal of Water Ecology 39(1): 16-22.

[14] Hu, H. J., Wei, Y. X. (2006): Freshwater algae in China: systems, classification and ecology. - Bei Jing: Science Press.

[15] Jia, X. H., Shi, D. J., Shi, H. J. (2011): Exploration on the causes of cyanobacteria bloom formation in lake Chaohu and "dominant species photosynthesis hypothesis". - Acta Ecologica Sinica 31(11): 2968-2977.

[16] Krause, G. H. (1988): Photo inhibition of photosynthesis. An evaluation of damaging and protective mechanisms. - Physiol Plantarum 74(3): 566-574.

[17] Li, Y. P., Tang, C. Y., Yu, Z. B. (2014): Correlations between algae and water quality: factors driving eutrophication in Lake Taihu, China. - International Journal of Environmental Science and Technology 11(1): 169-182.

[18] Lin, Z. F., Peng, C. L., Lin, G. Z. (1997): High light-induced changes of the differential absorbance at $505 \mathrm{~nm}$ and chlorophyll fluorescence in leaves and in green alga Dunaliella salina. - Journal of Tropical \& Subtropical Botany 3: 27-34.

[19] Liu, T., Ma, Z. L., Li, H. (2019): Effects of light intensity and nitrate level on growth and photosynthetic characteristics of Sargassum horneri. - Chinese Journal of Ecology 38(3): 762-769.

[20] Meng, S. L., Wang, J., Qiu, L. P. (2015): Effect of nitrogen and phosphorus mass concentrations on the growth and competition of Chlorella vulgaris and Anabaenasp strain PCC. - Ecology and Environment Sciences 24(4): 658-664.

[21] Michard, M., Aleya, L., Verneaux, J. (1996): Mass occurrence of the cyanobacteria Microcystis aeruginosa in the hypereutrophic Villrest Resevoir (Roanne, France): Usefulness of biyearly examination of N/P (nitrogen phosphorus) and P/C (protein/ carbohydrate) couplings. - Archiv für Hydrobiologie 135(3): 337-359.

[22] Muro-Pastor, M. I., Florencio, F. J. (2003): Regulation of ammonium assimilation in cyanobacteria. - Plant Physiology and Biochemistry 41: 595-603.

[23] Neil, J. M., Davis, T. W., Burford, M. A. (2013): The rise of harmful cyanobacteria blooms: the potential roles of eutrophication and climate change. - Harmful Algae 14: 313-334.

[24] Peng, N. Y., Dai, G. F., Zhang, W., Ge, G., Yang, P., Guo, C. J., Fang, Y. Y. (2018): Differences in nutrition condition and algae population in different areas of Poyang Lake. - Journal of Lake Sciences 30(5): 1295-1308.

[25] Shi, Z., Li, A. J., Zhang, Y. X., Tie, C., Zhao, Q. L., Li, Y., Jin, Y. (2014): Investigation on the composition of planktonic algae community in lake Dianchi. - Environmental monitoring in China 30(5): 131-124.

[26] Tang, Q. M., Chen, F., Xiang, W. Z. (2008): Effect of ammonium nitrogen on the growth, biochemical constitutes and toxin production of Microcystis aeroginosa FACHB905. Journal of Jinan University (Naturnal Science) 29(3): 290-294.

[27] Ting, C. S., Owens, T. G. (1992): Limitations of the pulse-modulated technique for measuring the fluorescence characteristics of algae. - Plant Physiology 100(1): 367-373. 
[28] Wang, L., Wang, G. X., Tang, X. Y. (2009): Inhibition of different types of aquatic plant communities on blue-green algae. - Biophysical Journal 28(12): 2567-2573.

[29] Wang, L. Y., Sang, M., Li, A. F. (2012): Effects of different nitrogen deficiency levels on growth and photosynthetic physiology of alga aureus. - Chinese Journal of Bioengineering 32(6): 48-56.

[30] Wang, P. F., Wang, Y. X., Wang, C. (2015): Ecological characteristics and environmental factors of phytoplankton during different seasons and in different parts of Taihu Lake. Fundamental and Applied Limnology 187(1): 33-42.

[31] Wang, M. W. (2018): Effects of environmental factors on growth and photosynthetic physiology of anabaena pseudo carp. - Qing Dao: Qingdao University of Technological.

[32] White, A. J., Critchley, C. (1999): Rapid light curves: a new fluorescence method to assess the state of the photosynthetic apparatus. - Photosynthesis Research 59(1): 63-72.

[33] Wu, J., Kong, Q., Yang, L. Y. (2009): Effect of the growth of Microcystis aeruginosa on the $\mathrm{pH}$ value and the nitrogen transformation in the medium. - Journal of Lake Sciences 21(1): 123-127.

[34] Wu, Q. L., Xin, P., Li, H. B., Ceng, J. (2013): Effects of steady state transformation of grass algae type on microbial structure and carbon cycling function of lake. - Microbiology bulletin 40(1): 87-97.

[35] Xu, D. Q., Zhang, Y. Z., Zhang, R. X. (1992): Photoinhibition of photosynthesis in plants. - Plant Physiology Communication 4: 237-243.

[36] Xu, H., Chen, D., Chen, J., Zhu, G. W., Qin, B. Q., Zhu, M. Y., Zhang, Y. L. (2019): Effects of nitrogen and phosphorus forms and concentrations on the growth of Microcystis aeruginosa and Scenedesmus obliquus. - China Environmental Science 39(6): 2560-2567.

[37] Yan, J. Q., Huang, X. X., Tao, Y. (2012): Suitable culture temperature and light intensity of five species of freshwater microalgae. - Journal of Ecology 31(5): 1104-1110.

[38] Yang, J., Wang, Z., Li, E. H., Song, X. X., Wang, X. L. (2015): Physiological characteristics of black algae and goldfish algae under different sediment conditions in lake Dianchi. - Wetland Science 13(4): 430-435.

[39] Young, E., Beardall, J. (2003): Rapid ammonium and nitrate induced perturbations to chl a flurescence in nitrogen stressed Dunaliella tertiolecata (Chlorophyta). - Journal of Phycology 39: 332-342.

[40] Yu, X., Zhu, Y. R., Wang, H. H. (2016): Release of amino acids from Microcystis aeruginosa and its contributions to organic matter. - Research of Environmental Sciences 29(3): 360-367.

[41] Zang, Z. R., Xie, X. J., Zhao, P. P. (2015): Effect of different temperatures and light conditions on the growth and fucoxanthin content of Phaeodactylum tricornutum. - Marine Sciences 39(7): 1-6.

[42] Zhang, Q. T., Wang, X. H., Lin, C. (2011): Effects of different nitrogen on proliferation of Microcystis aeruginosa. - Journal of Hydroecology 32(4): 115-120.

[43] Zhou, T., Zheng, Z. K., Feng, L. L. (2013): The different roles of ammonium and nitrate in the bloom self-maintenance of Lake Taihu. - China Environmental Science 33(2): 305311.

[44] Zhu, L. (2007): Effects of different phosphorus concentrations nitrogen sources and aeration modes on the growth of freshwater algae. - Chongqing: Chongqing university.

[45] Zhu, G. W., Qin, B. Q., Zhang, Y. L., Xu, H., Zhu, M. Y., Yang, H. W., Li, K. Y., Min, S. (2018): Shen Ruijie, Zhong Chunni. Variation and driving factors of nutrients and chlorophyll a concentration in northern region of Lake Taihu, China, 2005-2017. - Journal of Lake Sciences 30(2): 279-295. 